\title{
Transforming growth factor $\beta$ as regulator of cancer stemness and metastasis
}

\author{
Claudia Bellomo ${ }^{1,2}$, Laia Caja ${ }^{1,2}$ and Aristidis Moustakas ${ }^{\star 1,2}$ \\ ${ }^{1}$ Department of Medical Biochemistry and Microbiology, Science for Life Laboratory, Uppsala University, Box 582, SE 75123 Uppsala, \\ Sweden and ${ }^{2}$ Ludwig Institute for Cancer Research, Science for Life Laboratory, Uppsala University, Box 595, SE 75124 Uppsala, Sweden
}

Key elements of cancer progression towards metastasis are the biological actions of cancer stem cells and stromal cells in the tumour microenvironment. Cross-communication between tumour and stromal cells is mediated by secreted cytokines, one of which, the transforming growth factor $\beta$ (TGF $\beta$ ), regulates essentially every cell within the malignant tissue. In this article, we focus on the actions of TGF $\beta$ on cancer stem cells, cancer-associated fibroblasts and immune cells that assist the overall process of metastatic dissemination. We aim at illustrating intricate connections made by various cells in the tumour tissue and which depend on the action of TGF $\beta$.

\section{TGF $\beta$ IN CANCER}

Transforming growth factor $\beta$ (TGF $\beta$ ) is a secreted polypeptide discovered as a biological activity produced by tumour cells and capable of inducing oncogenic transformation of noncancerous cells in culture (Moses et al, 2016). Today we appreciate in great detail the mechanisms by which TGF $\beta$ and its diverse family members regulate embryonic developmental processes and why and how they are implicated essentially in many human diseases (Akhurst and Hata, 2012). The main reason for the overwhelming implication of TGF $\beta$ in human disease, including cancer, is the prominent role that TGF $\beta$ has on tissue homoeostasis and the fact that all chronic inflammatory and wounding processes activate this cytokine from the extracellular matrix (ECM) where it is deposited at abundant quantities and resides in an inactive form (Pickup et al, 2013). At the cellular level, TGF $\beta$ patrols several biological events either under physiological or pathological conditions such as the cell cycle and apoptosis, epithelial to mesenchymal transition (EMT) and ECM regulation (Akhurst and Hata, 2012). At the tissue and organ level, TGF $\beta$ regulates the differentiation and immunological response of $\mathrm{B}$ and $\mathrm{T}$ lymphocytes participating in the inflammatory cascade associated with cancer progression, and also regulates tissue interactions important during both embryonic organogenesis and cancer progression (Pickup et al, 2013).

Abnormalities in the TGF $\beta$ pathway relate to cancer development characteristic examples of which are certain hereditary cancer syndromes and many sporadic malignancies such as brain, breast, colon, liver, lung, prostate and haematopoetic malignancies. Abnormal TGF $\beta$ signalling additionally encompasses diverse developmental disorders, as for example, the craniofacial cleft palate syndrome, and the autosomal dominant abnormality of the Rendu-Osler-Weber syndrome; cardiovascular pathologies including atherosclerosis, hypertension and rare abnormalities of the vasculature such as aneurysms; connective tissue and bone diseases like the Marfan syndrome and osteoporosis; muscular and reproductive disorders (Gordon and Blobe, 2008). In cancer, the homoeostatic action of TGF $\beta$ explains why this cytokine acts as a tumour suppressor, by directing diverse cell types towards cell cycle arrest and apoptosis, whereas some of the genes encoding for TGF $\beta$ family ligands, receptors and Smads (downstream signalling proteins) become mutated in specific cancer types (Pickup et al, 2013). On the other hand, excessive amounts of TGF $\beta$ are expressed in the extracellular milieu of many tumours, and upon activation, induce sustained signalling in most types of malignancy analysed including brain, breast, liver, prostate, haematopoetic and other malignancies (Gordon and Blobe, 2008). In particular, TGF $\beta$ disrupts homoeostasis and enhances tumour progression via its ability to dedifferentiate many cell types, suppress the development of immune cells and indirectly allow vascular growth (Padua and Massagué, 2009).

Transforming growth factor $\beta$ signals via the same key signalling molecules under pro-tumourigenic and physiological homoeostatic conditions. However, the signalling outcome of these pathways may be very different in normal $v s$ malignant cells. The

*Correspondence: Professor A Moustakas; E-mail: aris.moustakas@imbim.uu.se

Received 19 February 2015; revised 14 July 2016; accepted 19 July 2016; published online 18 August 2016 
main difference between normal and tumour cell signalling relies in the prevalence of oncogenic molecules in the tumour cells, which might lead to disrupted cellular behaviour and pathogenic phenotypic outcome. The central mediators of TGF $\beta$ signalling activity involve receptors on the cell surface named type II (T $\beta$ RII) and type I (T $\beta \mathrm{RI})$, which bind the ligand as a heterotetrameric complex, leading to activation of their intrinsic protein kinase activity (Akhurst and Hata, 2012). T $\beta$ RII is the primary ligandbinding receptor that trans-phosphorylates $\mathrm{T} \beta \mathrm{RI}$, whose kinase activity becomes released from negative inhibition by chaperones. This causes the phosphorylation of Smad proteins - namely, Smad2 and Smad3 - which then assemble with Smad4 into a heteromeric complex. The latter accumulates on chromatin, resulting in an integrated action of chromatin-bound Smad complexes with the other signalling (non-Smad) molecules summarised below. Immediate early target genes of TGF $\beta$-Smad signalling include the inhibitory Smads, such as Smad7, which accumulate upon signalling and negatively regulate the pathway at the level of T $\beta$ RI degradation, Smad2/Smad3 phosphorylation by $\mathrm{T} \beta \mathrm{RI}$ and at the level of chromatin-bound Smad complexes, which are transcriptionally blocked by Smad7 (Akhurst and Hata, 2012).

Alternatively, the T $\beta$ RII-T $\beta$ RI receptor complex can recruit other signalling proteins, such as ubiquitin ligases, adaptors to protein and lipid kinases or small GTPases, which mediate diverse molecular activities collectively referred to as non-Smad signalling (Akhurst and Hata, 2012). The Smad and non-Smad signalling effectors most often coordinately regulate different sets of genes in a tissue-dependent and pathogenesis stage-dependent manner.

In the following sections, we will focus mostly on the biological actions of TGF $\beta$ but also make reference to signalling and mechanistic details wherever possible, pointing out how TGF $\beta$ can contribute to the biology of cancer stem cells (CSCs) and various stromal cell types in order to facilitate cancer metastasis. Due to limitations in the length of this article, we deliberately cover few instrumental cases from the older literature and base most of our examples on more recent but also few scientific reports.

\section{TGF $\beta$ SIGNALLING IN CANCER STEM CELLS}

Similar to its complex role in cancer progression, TGF $\beta$ can have a dual function concerning the biology of CSCs, inhibiting or sustaining their function. As an example, TGF $\beta$ has been reported to suppress breast cancer tumourigenesis via two independent mechanisms: by reducing the CSC/early progenitor pools or by promoting the differentiation of a committed but highly proliferative progenitor subset to a less proliferative and more differentiated one (Tang et al, 2007). In the presence of TGF $\beta$, the breast CSC population was less abundant and lost its self-renewal capacity, moreover this cytokine induced the expression of mucin1 and cytokeratin-18, luminal markers identifying slowly proliferating cells and negatively affected the expression of 'basal genes', such as cytokeratin-14 or frizzled-7, normally expressed by more proliferative cells (Tang et al, 2007). In a study of diffuse-type gastric carcinoma, TGF $\beta$ has been described to decrease the cancer-initiating cell population (side population), leading to a decrease in tumour formation and tumour size in vivo; this study pointed out how TGF $\beta$ acted via the negative regulation of ABCG2, a transmembrane transporter responsible for the active efflux of chemotherapeutics, probably conferring a metabolic or survival impairment to the CSCs, which were then eradicated (Ehata et al, 2011). The negative effect of TGF $\beta$ on the side population of gastric carcinoma can also be ascribed to the negative regulation on aldehyde dehydrogenase 1 (ALDH1) and REG4 (regenerating islet-derived family, member 4), which leads to a decrease in the $\mathrm{ALDH}_{1}{ }^{+}$population, correlating to poor prognosis in different tumours (Katsuno et al, 2012). The $\mathrm{ALDH}^{+}$population exhibits self-renewal capacity and displays tumour initiating and tumour progression potential in vivo and these CSC features are significantly suppressed by TGF $\beta$ (Katsuno et al, 2012).

On the other side, several studies underline how TGF $\beta$ has a positive role on the CSC population promoting or sustaining stemness of the pool of CSCs in diverse types of malignancy including breast cancer (Bruna et al, 2012; Lo et al, 2012; Bhola et al, 2013), liver cancer (You et al, 2010; Mima et al, 2012), gastric cancer (Hasegawa et al, 2014), skin cancer (Oshimori et al, 2015), glioblastoma (Ikushima et al, 2009; Peñuelas et al, 2009) and leukaemia (Naka et al, 2010). In hepatocellular carcinoma (HCC), TGF $\beta$ upregulates the expression of the stem cell marker CD133, via a Smad-dependent transcriptional mechanism and by promoting CD133 promoter demethylation based on a negative effect on the DNA methyltransferases DNMT1 and DNMT3 $\beta$, thus enhancing the tumourigenic potential of the $\mathrm{CD} 133^{+}$population in vivo (You et al, 2010). Another marker of HCC stem cells, the adhesion molecule CD44, potentiates TGF $\beta$ signalling and mesenchymal differentiation (Mima et al, 2012). Genetic ablation of T $\beta$ RII in mice, followed by chemically induced carcinogenesis of the bladder also attests to the positive role TGF $\beta$ signalling has in the generation of a bladder CSC population that promotes tumour invasiveness and aggressive behaviour (Liang et al, 2016).

In the brain tumour glioblastoma, TGF $\beta$ selectively induces selfrenewal of the glioma-initiating cells but not of normal glial progenitors, via the Smad-dependent induction of leukaemia inhibitory factor (LIF) and the sequential activation of the LIF-Janus kinase-STAT pathway (Peñuelas et al, 2009). This pathway leads to the increase in self-renewal potential (neurosphere formation), prevention of neurosphere differentiation in vitro and to higher tumour incidence and tumour size in vivo (Peñuelas et al, 2009). In this pathological scenario, an autocrine TGF $\beta$ loop maintains the self-renewal of glioma-initiating cells, acting on its direct target Sox4, which, in turn, binds to the stem cell transcription factor Oct4, and together induce expression of another stemness gene, Sox2 (Ikushima et al, 2009; Ikushima et al, 2011). In particular, the downregulation of Sox 4 and Sox 2 expression by TGF $\beta$ inhibitors diminishes stemness features and induces glioma CSC differentiation in vitro, whereas genetic attenuation of Sox4 leads to improved survival after intracranial injection of these glioma CSCs in vivo (Ikushima et al, 2009).

Leukaemia initiating cells (LICs) support the growth and relapse of chronic myeloid leukaemia; LICs with nuclear localisation of the transcription factor Foxo3a show decreased Akt kinase phosphorylation and exhibit characteristic enrichment in CSCs in this type of malignancy, because LIC apoptosis is suppressed and thus sustained progression of the malignancy is promoted (Naka et al, 2010). These findings propose that TGF $\beta$ regulates Akt phosphorylation and Foxo3a nuclear localisation, which is required for the stemness properties of LICs (Naka et al, 2010). Accordingly, a new therapeutic prospective can be based on the adjuvant administration of TGF $\beta$ receptor kinase inhibitor to the established imatinib treatment used against chronic myeloid leukaemia, in order to eradicate more effectively the LIC pool (Naka et al, 2010).

Crosstalk between TGF $\beta$ and other developmental pathways is also relevant. The cooperation between TGF $\beta$ and tumour necrosis factor $\alpha(\mathrm{TNF} \alpha)$ positively affects the acquisition of a CSC phenotype in breast cancer due to the induction of EMT. In particular, the TGF $\beta$-induced EMT-generated breast CSCs have a claudin-low phenotype - which is normally associated with mesenchymal features and more aggressive cancer behaviour and possess self-renewal potential, increased tumourigenicity in vivo and resistance to the chemotherapeutic drug oxaliplatin (Asiedu et al, 2011). Moreover, TGF $\beta$ cooperates with the WNT pathway in breast cancer to induce EMT and maintain the 
resulting mesenchymal and stem cell state in an autocrine fashion (Scheel et al, 2011). Blocking the TGF $\beta$-induced WNT pathway in this model of breast cancer, results in decreased cell migration and stem cell self-renewal in vitro, lowers tumourigenic potential and lowers macro and micrometastatic incidence in vivo. A screen for stemness genes enriched in non-small-cell lung carcinomas that exhibit high metastatic potential pointed to the importance of musashi-2, a regulator of protein synthesis (Kudinov et al, 2016). Attempting to genetically silence musashi-2 in these lung CSCs depleted the stem cell pool in part by causing induction of epithelial proteins, such as the junctional claudins, and by suppressing the translation of mRNAs for T $\beta$ RI and Smad3 and of Snail1 and Snail2, transcriptional mediators of EMT (Kudinov et al, 2016). This model suggests that TGF $\beta$ signalling promotes lung adenocarcinoma CSCs and their metastatic potential and that the TGF $\beta$ pathway is under the translational control of musashi-2.

\section{TGF $\beta$ IN CANCER METASTASIS}

Cancer metastasis is a multistep process that engages several cell types in addition to the primary tumour cell. Here we summarise evidence presented according to the major cell lineages that mediate metastatic dissemination. In recent years, different studies have demonstrated how TGF $\beta$ is implicated in metastasis (Padua and Massagué, 2009; Hansen et al, 2014). It has been reported that $\operatorname{TGF} \beta$ is able to create a tissue microenvironment permissive to the metastatic dissemination (Pickup et al, 2013), and that TGF $\beta$ can contribute to the local invasion, blood-borne metastatic dissemination and colonisation of distant organs (Calon et al, 2012; Calon et al, 2014).

TGF $\beta$ and fibroblasts in the tumour stroma. The origin of cancer-associated fibroblasts (CAFs) still remains an open question, due to the possible multiple origin of these cells and the differences described in CAF populations within specific tumour subtypes or even within distinct areas of the same tumour (Cirri and Chiarugi, 2011). Resident CAFs can originate from the differentiation of resident fibroblasts via the action of TGF $\beta$, and these CAFs then sustain the proliferative, migratory and invasive behaviour of cancer cells (Calon et al, 2014). Cancer-associated fibroblasts can also originate from the trans-differentiation of pericytes or inflammatory cells via the so-called mesenchymal to mesenchymal transition, which can be mediated by TGF $\beta$, among other cytokines (Buess et al, 2007; Cirri and Chiarugi, 2011). In addition, CAFs can be generated from bone marrow-derived mesenchymal stem cells (BM-MSC), which can be recruited at the tumour or inflammatory site and be committed to fibroblast differentiation by the locally released cytokines and growth factors (Karnoub et al, 2007; Mishra et al, 2008; Quante et al, 2011). At last, CAFs can derive from endothelial cells via the TGF $\beta 1$-induced endothelial mesenchymal transition process, or endEMT; in this event, the endothelial markers CD31/PECAM are downregulated, whereas the mesenchymal marker fibroblast-specific protein-1 is induced and the resulting CAFs localise at the invasive front of the tumour (Zeisberg et al, 2007).

A hallmark of activated fibroblasts or myofibroblasts is their ability to synthesise many ECM proteins and build a specialised cytoskeleton that incorporates the $\alpha$-smooth muscle actin ( $\alpha \mathrm{SMA}$ ). Transforming growth factor $\beta$ once again has a major role in mediating this terminal differentiation process. The TGF $\beta 1$ effect on pulmonary fibroblast to myofibroblast differentiation is illustrative of this process. Transforming growth factor $\beta$ drives pulmonary fibroblasts to acquire an irreversible post-mitotic phenotype associated with the induction of type I, II, III and IV collagen expression and secretion, reorganisation of the actin cytoskeleton, increase in $\alpha \mathrm{SMA}$ expression and incorporation of aSMA into stress fibres, one of the clear hallmarks of the myofibroblast phenotype. Interestingly enough, the Smad proteins differentially regulated the TGF $\beta 1$-induced morphological and functional changes, in particular Smad2 but not Smad3 affected aSMA, whereas both Smad2 and Smad3 affected collagen regulation (Evans et al, 2003).

In the context of cancer, early experiments using fibroblastspecific ablation of T $\beta$ RII in mice demonstrated that fibroblasts have homoeostatic roles within a tissue such as prostate or stomach, as loss of T $\beta$ RII led to excessive secretion of hepatocyte growth factor (HGF) and resulting in hyperproliferation of the epithelial cells in these tissues, supporting tumourigenic progression (Bhowmick et al, 2004). This experiment was one of the first that established the key role of stromal cells in controlling epithelial carcinogenesis via paracrine mechanisms. In the tumour microenvironment, TGF $\beta$ is produced by terminally differentiated CAFs, acting in an autocrine fashion on the same CAFs that have produced it (stromal TGF $\beta$-activation) while the epithelial cancer cells can also produce TGF $\beta$, which acts in a paracrine way on the fibroblasts (epithelial TGF $\beta$-activation) (Calon et al, 2014; Hawinkels et al, 2014). More specifically, CAFs can produce TGF $\beta 1$ via a Smad4-dependent autocrine signalling loop, which promotes their differentiation to myofibroblasts and supports a sustained acquired myofibroblast phenotype (Kojima et al, 2010). In particular, TGF $\beta 1$ promotes and crosstalks with the autocrine SDF-1 (stromal cell-derived factor 1)/CXCR-4 chemokine receptor pathway, and the latter helps to maintain high expression of TGF $\beta 1$, thus resulting in a synergistic positive effect on the myofibroblast functions and on their persistence in invasive breast cancer specimen (Kojima et al, 2010). Moreover, colorectal cancer cells secrete TGF $\beta 1$ and this leads to the hyperactivation of the TGF $\beta$ signalling pathway in the CAFs, causing enhanced expression of target genes such as the ECM modulators plasminogen activator inhibitor 1, matrix metalloproteases 2 and 9 (MMP-2, MMP-9) and $\alpha$ SMA (Hawinkels et al, 2014). Further evidence of the positive effect CAFs have on tumour cells has been described in colon cancer, where, CAFs activate extracellular $\operatorname{TGF} \beta$, which causes secretion of interleukin-11 (IL11) by the CAFs, that in turn triggers GP130/STAT3 signalling in the colorectal cancer cells (Calon et al, 2012). This mechanism confers a survival advantage to specific colorectal cancer clones with metastatic potential, whereas pharmacological blockade of the $\mathrm{TGF} \beta$ response in the stromal CAFs significantly impairs the tumour initiation (Calon et al, 2012). Furthermore, TGF $\beta$ enhances the attachment and co-migration of colon cancer cells and CAFs (Figure 1), positively affecting the metastatic burden of these colon carcinomas to the liver. Beyond this effect, TGF $\beta$ increases cancer cell proliferation in the primary tumour and in the metastasis, and TGF $\beta$-treated colon cancer cells more efficiently bind to endothelial cells, whereas CAFs exposed to TGF $\beta$ upregulate proteins involved in cell-cell attachment and cytokines that can sustain cancer cell survival during dissemination (Gonzalez-Zubeldia et $a l, 2015$ ). In a parallel scenario studied in bladder carcinoma, the urinary bladder CAFs oversecrete TGF $\beta 1$, which then causes EMT on the bladder epithelial cells via transcriptional induction of the long non-coding RNA (lncRNA) ZEB2NAT (Zhuang et al, 2015). ZEB2NAT positively regulates the expression of the pro-EMT transcriptional repressor ZEB2, which establishes the bladder carcinoma EMT and promotes the invasive behaviour of the tumour cells (Zhuang et al, 2015).

Furthermore, the TGF $\beta$ effect on CAFs appears to be associated to their metabolic reprogramming. Transforming growth factor $\beta$ activation by epithelial breast cancer cells MDA-MB-231 can induce differentiation of surrounding fibroblasts into CAFs, which causes their metabolic shift towards catabolic and glycolytic pathways - related with the processes of mitophagy and autophagy 


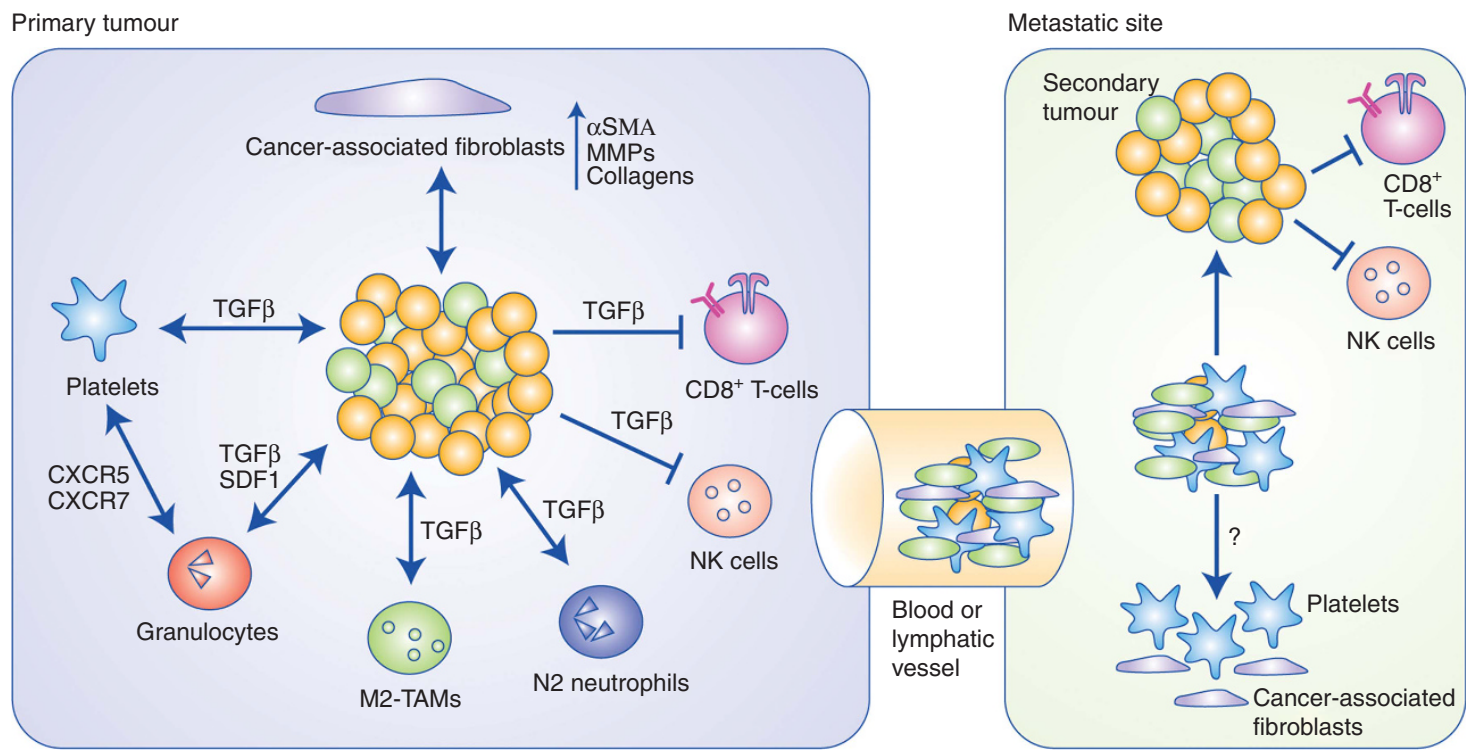

Figure 1. Pleiotropic effects of TGF $\beta$ in the tumour microenvironment. Representation of a primary tumour with cancer stem cells (CSCs) or metastasis-initiating cells (light green) and the bulk of the tumour cells (orange). Different cell types surrounding the tumour mass can positively contribute to tumour progression, invasiveness and metastatic dissemination, acting on the tumour cells but also receiving input from the tumour cells (bi-directional arrows). Cells that can inhibit tumour progression are linked to the tumour mass with a negative arrow. The contributions of TGF $\beta$ and additional cytokines and chemokines are highlighted next to each arrow. As graphic simplification, haematogenous or lymphatic metastatic dissemination shows solely CSCs co-migrating with stromal cells and platelets. At the secondary site, metastatic colonisation and growth is shown; whether stromal cells dissociate from the metastasising clonal population or whether they are replaced by new local stromal cells is currently unknown (?).

- as well as a decrease in mitochondrial activity and consequent oxidative stress (Guido et al, 2012). As a result, CAFs generate metabolites (L-lactate, ketone bodies and glutamine) that sustain the mitochondrial metabolism and the anabolic growth of the adjacent cancer cells at the expense of their own metabolic efficacy. In a parallel study of co-culture between NIH3T3 fibroblasts and 4T1 mouse breast cancer cells, the TGF $\beta$-induced autophagy on the fibroblasts (which resemble CAFs in this in vitro model) provided survival signals that enhanced the tumourigenic potential of the cancer cells in xenograft assays (Liu et al, 2016). A screen for chemical agents that could block the activation of CAFs by TGF $\beta$ revealed that cardiac glycosides, such as digoxin, which naturally regulate contractility of the heart muscle, effectively blocked CAF activation and cell contractility induced by TGF $\beta$ (Coleman et al, 2016). According to these views, CAFs serve as metabolic engines for the benefit of tumour growth and expansion, and inhibition of CAF function is beneficial for the host organism carrying the tumour.

Transforming growth factor $\beta$ not only acts on fibroblasts but can also have a role in increasing the myofibroblast population via recruiting and promoting differentiation of mesenchymal stem cells, thus sustaining the trophic role of myofibroblasts on tumour growth and supporting cancer cell invasiveness and subsequent metastatic dissemination. A recent study has pointed out how TGF $\beta$ released by prostate cancer cells via exosomes, but not soluble, secreted TGF $\beta$, can trigger the differentiation of BM-MSC into myofibroblasts (Chowdhury et al, 2015). In particular, exosomal TGF $\beta$ shifts the physiological adipogenic differentiation of BM-MSC towards the more pathological myofibroblast phenotype. The resulting myofibroblasts exhibit high expression of $\alpha$ SMA, MMPs, HGF and vascular endothelial growth factor-A (VEGF-A). The latter provides pro-angiogenic signals by acting on endothelial cells and experimentally exhibited a tumour promoting role based on a 3D co-culture model. Furthermore, osteopontin (OPN), which is normally present in the ECM, can influence TGF $\beta$ signalling. In particular, OPN triggers $\alpha_{\mathrm{v}} \beta_{3}$ integrin to induce the myeloid zinc finger 1 transcription factor causing an increase in TGF $\beta 1$ expression, and this allows the differentiation of mesenchymal stem cells into myofibroblasts (Weber et al, 2014). In this scenario, the obtained CAFs enhance the tumour occurrence in vivo when co-injected with breast cancer MDA-MB-231 cells, supporting the general concept of a trophic role of CAFs towards carcinoma cells.

TGF $\beta$ effect on immune cells in the tumour stroma. One of the main reasons behind tumour progression is the ineffective immune response against cancer (immune suppression), or the development of immune tolerance towards cancer-associated and cancerspecific antigens (Yang et al, 2010). It is well established that TGF $\beta$ is essential for the regulation of the innate and adaptive immune system under physiological or pathological conditions (Flavell et al, 2010). In cancer, in particular, it seems that TGF $\beta$ antagonises the effective innate and adaptive immunity responses, in order to promote cancer growth and metastatic dissemination, as depicted in Figure 1. A most illustrative example has been the complete loss of cancer growth in mice where T $\beta$ RII was knocked out in $\mathrm{T}$ lymphocytes, causing resistance to TGF $\beta$ and generation of regulatory $\mathrm{T}$ cells, which elicit a potent anti-tumoural response (Gorelik and Flavell, 2001). A recent example that expands on the previous study and underlines the significance of TGF $\beta$ effect on adaptive immunity provides more mechanistic insight. CD ${ }^{+} \mathrm{T}$ cells become unresponsive against tumour antigens due to the upregulation of the transcription factor FOXP1 (Stephen et al, 2014). FOXP1 blocks $\mathrm{CD}^{+}$activity due to a direct inhibitory effect on c-Jun, and upon TGF $\beta$ stimulation, FOXP1-Smad2/3 complexes accumulate in pre-activated $\mathrm{CD}^{+} \mathrm{T}$ cells, which results in an inhibitory effect on c-Myc expression and on cell proliferation. As a result, the tumour suppressive effect of $\mathrm{CD} 8^{+} \mathrm{T}$ cells is completely abrogated (Stephen et al, 2014). In addition to differentiation, TGF $\beta$ regulates the residence of $\mathrm{CD} 8{ }^{+} \mathrm{T}$ cells in epithelial tissues. In the skin, $\mathrm{CD} 8{ }^{+} \mathrm{T}$-cell residence depends on the proper expression of integrin receptor complexes on the surface 
of the epithelial cells, and on the regulated activation of latent TGF $\beta$ in the T-cell microenvironment (Mohammed et al, 2016). This event provides clues about the importance of a regulated degree of activation of TGF $\beta$ that can have homoeostatic functions, whereas upon deregulation of the balance, TGF $\beta$ can exhibit its pro-tumourigenic activities. Interestingly, it has been demonstrated how restricted loss of Smad4-dependent signalling in the T-cell population alters the physiological communication between adaptive immunity cells and tissue parenchyma (the epithelial cells in the latter retaining the normal function of Smad4), allowing the arousal of spontaneous epithelial cancers in the gastrointestinal tract, thus further underlining that a productive adaptive immune response is essential for effective tumour suppression (Kim et al, 2006).

Beyond $\mathrm{T}$ cells, macrophages have important roles in the tumour stroma. Macrophages can differentiate in two different lineages: M1 or classically activated, and M2 or alternatively activated, in response to different microenvironmental cues. The so-called tumour-associated macrophages (TAM) express a comparable phenotype to M2 macrophages and TGF $\beta 2$ can induce M2 macrophage polarisation, as described in Figure 1, whereas knock out of T $\beta$ RII results in less functional M2 macrophages (Gong et al, 2012). Interestingly, it has recently been described how M2-TAM can actively produce TGF $\beta$, which induces EMT and acquisition of cancer stem cell features in an in vitro model of HCC, leading to a worse prognosis in patients (Fan et al, 2014a). Moreover, $\operatorname{TGF} \beta$ has a similar effect on pro-tumourigenic N2 neutrophils and blocking TGF $\beta$ signalling switches the cellular phenotype to the anti-tumourigenic N1 neutrophil population (Pickup et al, 2013). In addition to this, TGF $\beta$ has an antagonistic effect on the activation of antigen-presenting dendritic cells and impairs the maturation of natural killer cells (Figure 1), thus inhibiting an effective innate response towards cancer (Pickup et al, 2013).

Breast cancer cells carrying knockout for T $\beta$ RII present more aggressive and highly metastatic behaviour to the lungs of mice compared with sibling carcinoma cells having wild-type T $\beta$ RII (Yang et al, 2008). The invasive periphery of such tumours is highly enriched in myeloid cells that express the Gr-1 and CD11b antigens on their surface, and their immunological ablation decreases the rate of metastatic dissemination. The T $\beta$ RII knockout cancer cells oversecrete chemokines, SDF-1 and CXCL5, which then attract the myeloid cells to the primary tumour; as a paracrine response, the myeloid cells oversecrete TGF $\beta 1$ and activate MMPs in the microenvironment, which facilitates invasiveness and dissemination (Yang et al, 2008). In particular, the lung tissue becomes remodelled in response to the extracellular activity of the MMPs secreted by the myeloid cells, which appear as groups intercalated with tumour colonies (Yan et al, 2010). Interestingly, genetic ablation of T $\beta$ RII in the myeloid cells suppresses the metastatic homing of breast cancer cells, emphasising the importance of this stromal cell type (Meng et al, 2016). Basic fibroblast growth factor (bFGF) could rescue the bone metastasis when injected intravenously in the mice with the T $\beta$ RII knockout myeloid cells, demonstrating that TGF $\beta$ signalling in the myeloid cells controls bFGF secretion, which then acts on the metastatic carcinoma cells to assist their homing (Meng et al, 2016). Similar studies with T $\beta$ RII ablation in the myeloid cells revealed a role for the chemokine CCL9, which is secreted by the TGF $\beta$-responsive myeloid cells and acts on the carcinoma cells promoting their survival and facilitating their metastatic homing (Yan et al, 2015). In agreement with the mouse model, the orthologuous to CCL9 human chemokine CCL23 is highly expressed in the peripheral blood myeloid cells from patients with aggressive cancer (Yan et al, 2015). The metastatic process is also linked to the action of platelets. Invading and intravasating breast cancer cells associate with platelets, which provide a rich source of TGF $\beta$, initiating breast epithelial EMT (Labelle et al, 2011). The interaction between platelets and breast cancer cells initiates upon unknown signalling pathways that mediate activation of the nuclear factor $\kappa \mathrm{B}$, which synergises with TGF $\beta$ signalling to elicit robust EMT, tumour cell migration and intravasation leading to lung metastasis. In addition, the tumour-associated platelets release chemokines CXCL5 and CXCL7, which recruit granulocytes (Labelle et al, 2011). The granulocytes sustain the metastatic colonisation via their enhanced MMP activity, and they co-migrate with the cancer cells through the lung capillaries.

Unexpectedly, the concept of TGF $\beta$-mediated immune suppression can also be exploited therapeutically, as demonstrated in therapy trials of the brain tumour glioblastoma using oncolytic Herpes simplex viral particles (Han et al, 2015). Pre-treatment of the tumour-bearing animal with a single dose of TGF $\beta$ prior to the administration of the oncolytic virus was able to effectively suppress resident natural killer and microglial cells so that the virus could elicit more robust cytotoxicity and limit tumour growth by prolonging life expectancy (Han et al, 2015).

TGF $\beta$ in metastatic dissemination. Transforming growth factor $\beta$ generally has a positive role in cancer dissemination and metastasis due to the shift of the TGF $\beta$ response from growth arrest to invasion and metastatic dissemination in the primary tumour (Roberts and Wakefield, 2003; Pickup et al, 2013). In addition, TGF $\beta$ can enhance metastasis by positively affecting neoangiogenesis and lymphangiogenesis, by promoting aggregation of cancer cells and CAFs, transendothelial migration of metastatic cell clones, by inducing microRNAs and lncRNAs with pro-metastatic effects and by acting on the tumour microenvironment in order to allow a permissive milieu to dissemination (Padua and Massagué, 2009; Peñuelas et al, 2009), as described in Figure 1.

Seminal studies aiming at identifying genes that control the metastatic behaviour of breast cancer cells that selectively colonise the bone identified a cohort of secreted factors that collectively contribute to bone destruction and generation of a permissive microenvironment for the establishment of metastatic cancer (Kang et al, 2003). The metastatic cells secrete polypeptides such as IL11, which mobilises osteoclasts to start damaging the bone, and connective tissue growth factor, which promotes local angiogenesis. The abundance of these two cytokines in the metastatic microenvironment is further boosted by the local release of TGF $\beta$ from rich bone depots, leading to an enhanced loop of cytokinebone destruction-TGF $\beta$ and back to cytokine release (Kang et al, 2003). Unexpectedly, the release of TGF $\beta$ from its storage in normal bone, during osteolysis promoted by the metastatic breast cancer cells, is also responsible for the deterioration of the associated muscle that eventually leads to cachexia (Waning et al, 2015). Transforming growth factor $\beta$ acting on muscle cells induces expression of the NADPH oxidase Nox4, which oxidises signalling proteins in the muscle, including the ryanodine receptor and the calcium release channel, both playing critical roles in maintaining physiological calcium levels for the function of the muscle. The resulting deterioration in calcium availability weakens the force-generating capacity of the muscle and initiates cachexia (Waning et al, 2015).

More intriguing is the mechanism by which TGF $\beta$ acting in the primary breast tumour induces angiopoietin-like 4 , which is retained by the metastatic cancer cells and facilitates their extravasation specifically to the lung (Padua et al, 2008). Angiopoietin-like 4 released from metastatic cells disrupts endothelial cell-cell adhesions in lung capillaries, promoting delivery of the tumour cells to the distant tissue. This is an example whereby the action of TGF $\beta$ in the primary tumour, conditions the cancer cells with capacities for manipulation of the microenvironment at the target metastatic site. Transforming growth factor $\beta$ can also promote the formation of a pro-metastatic 
extracellular environment and can actively influence the interaction between cancer cells with ECM and stromal cells. It has been recently reported how $\mathrm{TGF} \beta$ can induce the expression of the metalloprotease ADAM17, which promotes the release of the adhesion protein ALCAM from metastatic prostate cells in vivo and in vitro (Hansen et al, 2014). ALCAM shedding appears to be required for the effective prostate cancer metastasis to the bone and positively correlates with the tumour burden in subcutaneous and orthotopic in vivo models. Moreover, the tumour-shed ALCAM mediates TGF $\beta$-induced migration and bone metastasis without affecting primary tumour growth; persistent ALCAM shedding in the metastatic bone microenvironment also promotes the survival and proliferation of metastatic cells (Hansen et al, 2014). An alternative pro-metastatic mechanism induced by TGF $\beta$ signalling in prostate carcinomas involves one of the most highly sensitive target genes of the TGF $\beta$ pathway, one encoding for the plasma membrane protein PMEPA1 (Fournier et al, 2015). The regulatory function of PMEPA1 involves interaction with Smad proteins and ubiquitin ligases, causing a relative decrease in TGF $\beta$ signalling. Interestingly, upon prostate cancer metastasis, PMEPA1 expression is downregulated by as yet uncharacterised mechanisms, causing a release of TGF $\beta /$ Smad signalling from the negative control of PMEPA1 and promoting the homing of metastatic cells to bone (Fournier et al, 2015).

Moreover, TGF $\beta$ and the TGF $\beta$ co-receptor family member Endoglin can promote tumour angiogenesis, thus positively affecting metastatic dissemination (Pardali and ten Dijke, 2009). Transforming growth factor $\beta$ can directly activate endothelial cell proliferation and migration, promotes the capillary formation in vitro and neoangiogenesis in vivo (Pardali and ten Dijke, 2009). Moreover, this cytokine can induce the expression of VEGF, the major growth factor promoting vascularisation, and this can be promoted by hypoxia, a frequent condition in the microenvironment of growing tumours (Pardali and ten Dijke, 2009). Furthermore, TGF $\beta$ can recruit inflammatory cells that secrete pro-angiogenic factors and it can promote the synthesis of MMP, integrins and plasminogen activators, which have an important role in the initiation and progression of angiogenesis (Pardali and ten Dijke, 2009).

The importance of TGF $\beta$ for the sprouting of lymphatic vessels and of the lymphatic network in the skin has also been reported, and furthermore, how inhibition of the TGF $\beta$ pathway allows the lymphatic microvascular endothelial cells to migrate, proliferate and form functional lymphatic vessels in response to the growth factor VEGF-C, an important promoter of lymphangiogenesis (Oka et al, 2008; James et al, 2013). These findings suggest an inhibitory role of TGF $\beta$ on lymphangiogenesis in this particular context. Intriguingly, the transcription factor SIX1 has been described to enhance the Smad-dependent TGF $\beta$ signalling and this results in the transcriptional induction of the growth factor VEGF-C, and promotion of lymphatic metastatic dissemination, thus pointing out the mechanism by which TGF $\beta$ impacts on this physiological process (James et al, 2013; Liu et al, 2014). In addition, metastasis of breast cancer cells that undergo EMT through the lymphatic system also involves upregulation of the chemokine CCL21, which is secreted by lymphatic endothelial cells responding to TGF $\beta$ (Pang et al, 2016). CCL21 signals by binding to its receptor CCR7, whose expression is also upregulated by TGF $\beta$ on the surface of the breast carcinoma cells that exhibit EMT (Pang et al, 2016). This mechanism attracts the metastatic cells to the lymphatic vessels for intravasation and subsequent dissemination to local lymph nodes.

Modern techniques, such as intravital microscopy, allow detection of a switch in TGF $\beta$ signalling during metastasis. It has been elegantly described how TGF $\beta$ differentially regulates cell migration, affecting the type of systemic dissemination of tumour cells: cancer cells exhibiting high levels of TGF $\beta$ activity are highly motile and can intravasate as single cells, whereas cells with lower TGF $\beta$ activity are characterised by cohesive and collective movement, which allows their lymphatic dissemination (Giampieri et al, 2010). Moreover, it has been underlined that only cells with high TGF $\beta$ levels are poorly differentiated and are actually able to migrate, whereas TGF $\beta$ signalling cannot cause the same effect in highly differentiated cells. Reasonably, it is important for TGF $\beta$ signalling to be switched off at the secondary tumour site in order to enable proliferation of the metastatic cells (Giampieri et al, 2010). Three dimensional co-culture studies also demonstrated that mesenchymal stem cells that secrete TGF $\beta$ promote a characteristic directional migration of breast carcinoma cells, which exhibit elongated morphology and develop strong traction between them, factors that facilitate tumour cell invasiveness (McAndrews et al, 2015).

Transforming growth factor $\beta$ is classically associated with the induction of EMT and with migratory and invasive cell properties, which allows the local and systemic dissemination of selected clones of primary tumour cells in order to establish metastasis at a distant organ. As an example, in HCC, the tyrosine kinase receptor Axl induces and modulates the autocrine $\operatorname{TGF} \beta$ pathway and this positively correlates with HCC invasion, transendothelial invasion and metastatic dissemination in vivo (Reichl et al, 2015). Such a role of Axl downstream of TGF $\beta$ has also been observed in breast carcinoma ( $\mathrm{Li}$ et $\mathrm{al}, 2015)$ and supports the double-positive loop whereby tumour progression may be promoted by the Axl-TGF $\beta$ Axl double axis, a prominent target for new therapeutic intervention. Intriguingly, TGF $\beta$ signalling also induces expression of Axl in the pancreas and the skin under non-cancerous, homoeostatic conditions (Bauer et al, 2012).

In breast cancer, the nuclear factor NR4A1 activates TGF $\beta$ / Smad signalling by increasing the half-life of T $\beta$ RI on the plasma membrane, and by inducing Smad7 degradation via an AXIN2RNF12/ARKADIA ubiquitylation machinery in cancer cells and in CAFs (Zhou et al, 2014). This results in the acquisition of TGF $\beta$ induced EMT features and in the increase of cell migration, invasion and metastasis in vitro and in vivo. Interestingly, NR4A1 appears to integrate signals from different pathways as follows: it mediates the IL1 $\beta$ and TNF $\alpha$ actions on EMT and cancer cell migration in vivo; and it promotes TGF $\beta$ signalling, emphasising the cooperative role of these cytokines in malignancy.

Non-coding RNAs in metastatic dissemination. TGF $\beta$ can also have a positive role on metastatic dissemination via the induction

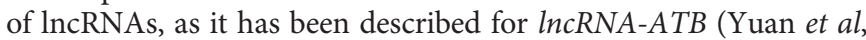
2014). LncRNA-ATB upregulates the homeobox and zinc finger transcription factors ZEB1 and ZEB2 due to a competitive effect on the microRNA (miR)-200 family, which base pairs with the IncRNA-ATB, thus permitting ZEB1/ZEB2 synthesis and resulting in EMT and invasion of HCC cells. In this respect, $\operatorname{lncRNA-ATB}$ functionally mimics the action of ZEB2NAT, which operates in CAFs (Zhuang et al, 2015), as described earlier. LncRNA-ATB also binds the IL11 mRNA promoting an IL11-STAT3 signalling loop responsible for dissemination of HCC cells. This effect is independent from the miR-200 inhibition and contributes to an increased colonisation and metastasis occurrence in the lungs. Bladder cancer metastasis is as well promoted in part due to the TGF $\beta$-induced upregulation of the IncRNA Malat1 (Fan et al, 2014b). Upon TGF $\beta$ stimulation Malat1 associates with the Polycomb corepressor subunit Suz12, and this induces an EMT phenotype in bladder cancer, concerning in particular the repression of E-cadherin, and promoting migration and invasion in vivo (Fan et al, 2014b). Malat1 and its protein partner Suz12 appear to be crucial for this process, as their silencing abrogates the migratory and invasive properties promoted by TGF $\beta$.

Similar mechanisms involve microRNAs, such as the oncogenic $m i R-155$, which negatively regulates the expression of the 
transcription factor $\mathrm{C} / \mathrm{EBP} \beta$, a differentiation factor for the mammary epithelium (Johansson et al, 2013). As a consequence, breast cancer cells become insensitive to the TGF $\beta$ growth inhibitory effects and acquire EMT features, promoting their invasion and dissemination to the lungs of tumour-bearing mice (Johansson et al, 2013). In particular, when miR-155 silences $\mathrm{C} / \mathrm{EBP} \beta$ in the cancer cells, autocrine production of TGF $\beta 1$ or downstream phosphorylation of Smad3 is not perturbed, confirming that the in vivo effects are due to a switch in TGF $\beta$ response, and not due to ineffective TGF $\beta$ signalling. In a distinct mechanism, TGF $\beta$ signalling is enhanced in pancreatic adenocarcinomas in part because of the downregulation of the $m i R-323-3 p$ (Wang et al, 2016). The miR-323-3p downregulates expression of Smad2 and Smad3 and relatively high expression of this microRNA maintains a controlled, low activity of TGF $\beta$ signalling that serves homoeostatic functions. An epigenetic mechanism affecting Smad2 and Smad3 expression operates in lung adenocarcinomas (Tang et al, 2015). High TGF $\beta$ signalling promoting EMT and invasive, metastatic growth is achieved by high expression of Smad2 and Smad3, which is coordinately regulated by the cytoplasmic protein profilin-2. Tumour cells overexpress profilin-2, which sequesters the histone deacetylase HDAC1 in the cytoplasm, thus releasing the transcriptional control from Smad2 and Smad3, which also become overexpressed (Tang et al, 2015). Whether this mechanism in lung carcinomas involves non-coding RNAs remains to be examined.

Conversely, microRNAs can be positive regulators of TGF $\beta$ signalling by targeting the negative feedback mechanism of this pathway that is mediated by Smad7. Such an example is the miR-1269, which downregulates Smad7 and the transcription factor HoxD10 in colorectal cancers (Bu et al, 2015). By negatively affecting Smad7 expression, miR-1269 promotes TGF $\beta$ signalling and colorectal carcinoma metastasis to the liver, whereas TGF $\beta$ itself transcriptionally induces expression of the miR-1269, forming a feed-forward signalling loop that counteracts the classical negative feedback loop of Smad7 in the context of tumour metastasis (Bu et al, 2015).

\section{CONCLUSION}

TGF $\beta$ signalling is disregulated in different types of cancers, thus affecting the overall progression to malignancy. For this reason TGF $\beta$ has been considered a valuable target in oncology. Current approaches with TGF $\beta$ inhibitors, such as the low molecular weight T $\beta$ RI kinase inhibitor LY2109761, revealed an acquired chemoresistance in cancer patients (Akhurst and Hata, 2012). However, a careful clinical study where the dose of the improved $\mathrm{T} \beta \mathrm{RI}$ inhibitor LY2157299 was tested in glioma patients revealed strong beneficial effects and complete lack of cardiotoxic side effects revealing the promise of anti-TGF $\beta$ therapy (Rodon et al, 2015). Despite this recent progress, another way to obtain effective therapeutic treatment could be to apply personalised medicine based on the genetic background of the individual, which can define the TGF $\beta$ response; this approach is viewed as particularly challenging considering the intricacy of this pathway (Akhurst and Hata, 2012), but it may soon gain applicability in the oncology clinic. Another effective approach could consist in finding biomarkers related to TGF $\beta$ signalling - as for example USP15 in glioblastoma - which can be used to discriminate patient populations into those that are responsive and non-responsive to $\operatorname{TGF} \beta$, in order to apply targeted therapeutic approaches only to the responsive cohort (Eichhorn et al, 2012). Similarly, a strategy that can be potentially useful to stratify colorectal cancer patients according to their prognosis has been recently suggested (Calon et al, 2015). This relies in a gene signature that is induced by TGF $\beta$ specifically in the colorectal tumour stroma (i.e. mainly the CAFs), rather than in the epithelial tumour, and such an approach might prove invaluable for the future use of TGF $\beta$ signalling inhibitors, so that the inhibitors selectively interfere with the crosstalk between cancer cells and the tumour stroma. All such cases convincingly raise the $\operatorname{TGF} \beta$ pathway as a promising therapeutic target against all types of tumours, although deeper insight into the means for achieving personalised therapeutic benefits has to be gained.

\section{ACKNOWLEDGEMENTS}

We acknowledge funding by the Ludwig Institute for Cancer Research, the Swedish Cancer Society, the Swedish Research Council and the Marie Curie Initial Training Network 'IT-Liver' under the European Union FP7 program. We thank all past and present members of our group for their contributions to the scientific work emanating from our laboratory. Due to space limitations, we have been unable to include all relevant publications in our discussion. We apologise to those authors whose relevant work has not been included in this review article.

\section{CONFLICT OF INTEREST}

The authors declare no conflict of interest.

\section{REFERENCES}

Akhurst RJ, Hata A (2012) Targeting the TGF $\beta$ signalling pathway in disease. Nat Rev Drug Discov 11: 790-811.

Asiedu MK, Ingle JN, Behrens MD, Radisky DC, Knutson KL (2011) TGF $\beta /$ $\mathrm{TNF} \alpha$-mediated epithelial-mesenchymal transition generates breast cancer stem cells with a claudin-low phenotype. Cancer Res 71: 4707-4719.

Bauer T, Zagorska A, Jurkin J, Yasmin N, Koffel R, Richter S, Gesslbauer B, Lemke G, Strobl H (2012) Identification of Axl as a downstream effector of TGF- $\beta 1$ during Langerhans cell differentiation and epidermal homeostasis. J Exp Med 209: 2033-2047.

Bhola NE, Balko JM, Dugger TC, Kuba MG, Sanchez V, Sanders M, Stanford J, Cook RS, Arteaga CL (2013) TGF- $\beta$ inhibition enhances chemotherapy action against triple-negative breast cancer. J Clin Invest 123: 1348-1358.

Bhowmick NA, Chytil A, Plieth D, Gorska AE, Dumont N, Shappell S, Washington MK, Neilson EG, Moses HL (2004) TGF- $\beta$ signaling in fibroblasts modulates the oncogenic potential of adjacent epithelia. Science 303: $848-851$.

Bruna A, Greenwood W, Le Quesne J, Teschendorff A, Miranda-Saavedra D, Rueda OM, Sandoval JL, Vidakovic AT, Saadi A, Pharoah P, Stingl J, Caldas C (2012) TGF $\beta$ induces the formation of tumour-initiating cells in claudin low breast cancer. Nat Commun 3: 1055.

Bu P, Wang L, Chen KY, Rakhilin N, Sun J, Closa A, Tung KL, King S, Kristine Varanko A, Xu Y, Huan Chen J, Zessin AS, Shealy J, Cummings B, Hsu D, Lipkin SM, Moreno V, Gumus ZH, Shen X (2015) miR-1269 promotes metastasis and forms a positive feedback loop with TGF- $\beta$. Nat Commun 6: 6879 .

Buess M, Nuyten DS, Hastie T, Nielsen T, Pesich R, Brown PO (2007) Characterization of heterotypic interaction effects in vitro to deconvolute global gene expression profiles in cancer. Genome Biol 8: R191.

Calon A, Espinet E, Palomo-Ponce S, Tauriello DV, Iglesias M, Cespedes MV, Sevillano M, Nadal C, Jung P, Zhang XH, Byrom D, Riera A, Rossell D, Mangues R, Massagué J, Sancho E, Batlle E (2012) Dependency of colorectal cancer on a TGF- $\beta$-driven program in stromal cells for metastasis initiation. Cancer Cell 22: 571-584.

Calon A, Lonardo E, Berenguer-Llergo A, Espinet E, Hernando-Momblona X, Iglesias M, Sevillano M, Palomo-Ponce S, Tauriello DV, Byrom D, Cortina C, Morral C, Barcelo C, Tosi S, Riera A, Attolini CS, Rossell D, Sancho E, Batlle E (2015) Stromal gene expression defines poor-prognosis subtypes in colorectal cancer. Nat Genet 47: 320-329. 
Calon A, Tauriello DV, Batlle E (2014) TGF- $\beta$ in CAF-mediated tumor growth and metastasis. Semin Cancer Biol 25: 15-22.

Chowdhury R, Webber JP, Gurney M, Mason MD, Tabi Z, Clayton A (2015) Cancer exosomes trigger mesenchymal stem cell differentiation into pro-angiogenic and pro-invasive myofibroblasts. Oncotarget 6: 715-731.

Cirri P, Chiarugi P (2011) Cancer associated fibroblasts: the dark side of the coin. Am J Cancer Res 1: 482-497.

Coleman DT, Gray AL, Stephens CA, Scott ML, Cardelli JA (2016) Repurposed drug screen identifies cardiac glycosides as inhibitors of TGF$\beta$-induced cancer-associated fibroblast differentiation. Oncotarget; e-pub ahead of print 6 April 2016; doi:10.18632/oncotarget.8609.

Ehata S, Johansson E, Katayama R, Koike S, Watanabe A, Hoshino Y, Katsuno Y, Komuro A, Koinuma D, Kano MR, Yashiro M, Hirakawa K, Aburatani H, Fujita N, Miyazono K (2011) Transforming growth factor- $\beta$ decreases the cancer-initiating cell population within diffuse-type gastric carcinoma cells. Oncogene 30: 1693-1705.

Eichhorn PJ, Rodon L, Gonzalez-Junca A, Dirac A, Gili M, Martinez-Saez E, Aura C, Barba I, Peg V, Prat A, Cuartas I, Jimenez J, Garcia-Dorado D, Sahuquillo J, Bernards R, Baselga J, Seoane J (2012) USP15 stabilizes TGF$\beta$ receptor I and promotes oncogenesis through the activation of TGF- $\beta$ signaling in glioblastoma. Nat Med 18: 429-435.

Evans RA, Tian YC, Steadman R, Phillips AO (2003) TGF- $\beta$ 1-mediated fibroblast-myofibroblast terminal differentiation-the role of Smad proteins. Exp Cell Res 282: 90-100.

Fan QM, Jing YY, Yu GF, Kou XR, Ye F, Gao L, Li R, Zhao QD, Yang Y, Lu ZH, Wei LX (2014a) Tumor-associated macrophages promote cancer stem cell-like properties via transforming growth factor- $\beta 1$-induced epithelial-mesenchymal transition in hepatocellular carcinoma. Cancer Lett 352: 160-168.

Fan Y, Shen B, Tan M, Mu X, Qin Y, Zhang F, Liu Y (2014b) TGF- $\beta$-induced upregulation of malat1 promotes bladder cancer metastasis by associating with suz12. Clin Cancer Res 20: 1531-1541.

Flavell RA, Sanjabi S, Wrzesinski SH, Licona-Limon P (2010) The polarization of immune cells in the tumour environment by TGF $\beta$. Nat Rev Immunol 10: $554-567$.

Fournier PG, Juarez P, Jiang G, Clines GA, Niewolna M, Kim HS, Walton HW, Peng XH, Liu Y, Mohammad KS, Wells CD, Chirgwin JM, Guise TA (2015) The TGF- $\beta$ Signaling regulator PMEPA1 suppresses prostate cancer metastases to bone. Cancer Cell 27: 809-821.

Giampieri S, Pinner S, Sahai E (2010) Intravital imaging illuminates transforming growth factor $\beta$ signaling switches during metastasis. Cancer Res 70: 3435-3439.

Gong D, Shi W, Yi SJ, Chen H, Groffen J, Heisterkamp N (2012) TGF $\beta$ signaling plays a critical role in promoting alternative macrophage activation. BMC Immunol 13: 31.

Gonzalez-Zubeldia I, Dotor J, Redrado M, Bleau AM, Manrique I, de Aberasturi AL, Villalba M, Calvo A (2015) Co-migration of colon cancer cells and CAFs induced by TGF $\beta$ enhances liver metastasis. Cell Tissue Res 359: 829-839.

Gordon KJ, Blobe GC (2008) Role of transforming growth factor- $\beta$ superfamily signaling pathways in human disease. Biochim Biophys Acta 1782: 197-228.

Gorelik L, Flavell RA (2001) Immune-mediated eradication of tumors through the blockade of transforming growth factor- $\beta$ signaling in T cells. Nat Med 7: 1118-1122.

Guido C, Whitaker-Menezes D, Capparelli C, Balliet R, Lin Z, Pestell RG, Howell A, Aquila S, Ando S, Martinez-Outschoorn U, Sotgia F, Lisanti MP (2012) Metabolic reprogramming of cancer-associated fibroblasts by TGF$\beta$ drives tumor growth connecting TGF- $\beta$ signaling with 'Warburg-like' cancer metabolism and L-lactate production. Cell Cycle 11: 3019-3035.

Han J, Chen X, Chu J, Xu B, Meisen WH, Chen L, Zhang L, Zhang J, He X, Wang QE, Chiocca EA, Kaur B, Caligiuri MA, Yu J (2015) TGF $\beta$ treatment enhances glioblastoma virotherapy by inhibiting the innate immune response. Cancer Res 75: 5273-5282.

Hansen AG, Arnold SA, Jiang M, Palmer TD, Ketova T, Merkel A, Pickup M, Samaras S, Shyr Y, Moses HL, Hayward SW, Sterling JA, Zijlstra A (2014) ALCAM/CD166 is a TGF- $\beta$-responsive marker and functional regulator of prostate cancer metastasis to bone. Cancer Res 74: 1404-1415.

Hasegawa T, Yashiro M, Nishii T, Matsuoka J, Fuyuhiro Y, Morisaki T, Fukuoka T, Shimizu K, Shimizu T, Miwa A, Hirakawa K (2014) Cancerassociated fibroblasts might sustain the stemness of scirrhous gastric cancer cells via transforming growth factor- $\beta$ signaling. Int $J$ Cancer 134: 1785-1795.
Hawinkels LJAC, Paauwe M, Verspaget HW, Wiercinska E, van der Zon JM, van der Ploeg K, Koelink PJ, Lindeman JHN, Mesker W, ten Dijke P, Sier CFM (2014) Interaction with colon cancer cells hyperactivates TGF- $\beta$ signaling in cancer-associated fibroblasts. Oncogene 33: 97-107.

Ikushima H, Todo T, Ino Y, Takahashi M, Miyazawa K, Miyazono K (2009) Autocrine TGF- $\beta$ signaling maintains tumorigenicity of gliomainitiating cells through Sry-related HMG-box factors. Cell Stem Cell 5: 504-514.

Ikushima H, Todo T, Ino Y, Takahashi M, Saito N, Miyazawa K, Miyazono K (2011) Glioma-initiating cells retain their tumorigenicity through integration of the Sox axis and Oct4 protein. J Biol Chem 286: 41434-41441.

James JM, Nalbandian A, Mukouyama YS (2013) TGF $\beta$ signaling is required for sprouting lymphangiogenesis during lymphatic network development in the skin. Development 140: 3903-3914.

Johansson J, Berg T, Kurzejamska E, Pang MF, Tabor V, Jansson M, Roswall P, Pietras K, Sund M, Religa P, Fuxe J (2013) MiR-155-mediated loss of C/EBP $\beta$ shifts the TGF- $\beta$ response from growth inhibition to epithelial-mesenchymal transition, invasion and metastasis in breast cancer. Oncogene 32: 5614-5624.

Kang Y, Siegel PM, Shu W, Drobnjak M, Kakonen SM, Cordon-Cardo C, Guise TA, Massagué J (2003) A multigenic program mediating breast cancer metastasis to bone. Cancer Cell 3: 537-549.

Karnoub AE, Dash AB, Vo AP, Sullivan A, Brooks MW, Bell GW, Richardson AL, Polyak K, Tubo R, Weinberg RA (2007) Mesenchymal stem cells within tumour stroma promote breast cancer metastasis. Nature 449: $557-563$

Katsuno Y, Ehata S, Yashiro M, Yanagihara K, Hirakawa K, Miyazono K (2012) Coordinated expression of REG4 and aldehyde dehydrogenase 1 regulating tumourigenic capacity of diffuse-type gastric carcinomainitiating cells is inhibited by TGF- $\beta$. J Pathol 228: 391-404.

Kim BG, Li C, Qiao W, Mamura M, Kasprzak B, Anver M, Wolfraim L, Hong S, Mushinski E, Potter M, Kim SJ, Fu XY, Deng C, Letterio JJ (2006) Smad4 signalling in $\mathrm{T}$ cells is required for suppression of gastrointestinal cancer. Nature 441: 1015-1019.

Kojima Y, Acar A, Eaton EN, Mellody KT, Scheel C, Ben-Porath I, Onder TT, Wang ZC, Richardson AL, Weinberg RA, Orimo A (2010) Autocrine TGF- $\beta$ and stromal cell-derived factor-1 (SDF-1) signaling drives the evolution of tumor-promoting mammary stromal myofibroblasts. Proc Natl Acad Sci USA 107: 20009-20014.

Kudinov AE, Deneka A, Nikonova AS, Beck TN, Ahn YH, Liu X, Martinez CF, Schultz FA, Reynolds S, Yang DH, Cai KQ, Yaghmour KM, Baker KA, Egleston BL, Nicolas E, Chikwem A, Andrianov G, Singh S, Borghaei H, Serebriiskii IG, Gibbons DL, Kurie JM, Golemis EA, Boumber Y (2016) Musashi-2 (MSI2) supports TGF- $\beta$ signaling and inhibits claudins to promote non-small cell lung cancer (NSCLC) metastasis. Proc Natl Acad Sci USA 113: 6955-6960.

Labelle M, Begum S, Hynes RO (2011) Direct signaling between platelets and cancer cells induces an epithelial-mesenchymal-like transition and promotes metastasis. Cancer Cell 20: 576-590.

Li Y, Jia L, Liu C, Gong Y, Ren D, Wang N, Zhang X, Zhao Y (2015) Axl as a downstream effector of TGF- $\beta 1$ via PI3K/Akt-PAK1 signaling pathway promotes tumor invasion and chemoresistance in breast carcinoma. Tumour Biol 36: 1115-1127.

Liang Y, Zhu F, Zhang H, Chen D, Zhang X, Gao Q, Li Y (2016) Conditional ablation of TGF- $\beta$ signaling inhibits tumor progression and invasion in an induced mouse bladder cancer model. Sci Rep 6: 29479.

Liu D, Li L, Zhang XX, Wan DY, Xi BX, Hu Z, Ding WC, Zhu D, Wang XL, Wang W, Feng ZH, Wang H, Ma D, Gao QL (2014) SIX1 promotes tumor lymphangiogenesis by coordinating TGF $\beta$ signals that increase expression of VEGF-C. Cancer Res 74: 5597-5607.

Liu FL, Mo EP, Yang L, Du J, Wang HS, Zhang H, Kurihara H, Xu J, Cai SH (2016) Autophagy is involved in TGF- $\beta 1$-induced protective mechanisms and formation of cancer-associated fibroblasts phenotype in tumor microenvironment. Oncotarget 7: 4122-4141.

Lo PK, Kanojia D, Liu X, Singh UP, Berger FG, Wang Q, Chen H (2012) CD49f and CD61 identify Her2/neu-induced mammary tumor-initiating cells that are potentially derived from luminal progenitors and maintained by the integrin-TGF $\beta$ signaling. Oncogene 31: 2614-2626.

McAndrews KM, McGrail DJ, Ravikumar N, Dawson MR (2015) Mesenchymal stem ells induce directional migration of invasive breast cancer cells through TGF- $\beta$. Sci Rep 5: 16941.

Meng X, Vander Ark A, Lee P, Hostetter G, Bhowmick NA, Matrisian LM, Williams BO, Miranti CK, Li X (2016) Myeloid-specific TGF- $\beta$ signaling 
in bone promotes basic-FGF and breast cancer bone metastasis. Oncogene 35: $2370-2378$.

Mima K, Okabe H, Ishimoto T, Hayashi H, Nakagawa S, Kuroki H, Watanabe M, Beppu T, Tamada M, Nagano O, Saya H, Baba H (2012) CD44s regulates the TGF- $\beta$-mediated mesenchymal phenotype and is associated with poor prognosis in patients with hepatocellular carcinoma. Cancer Res 72: 3414-3423.

Mishra PJ, Mishra PJ, Humeniuk R, Medina DJ, Alexe G, Mesirov JP, Ganesan S, Glod JW, Banerjee D (2008) Carcinoma-associated fibroblastlike differentiation of human mesenchymal stem cells. Cancer Res 68 : 4331-4339.

Mohammed J, Beura LK, Bobr A, Astry B, Chicoine B, Kashem SW, Welty NE, Igyarto BZ, Wijeyesinghe S, Thompson EA, Matte C, Bartholin L, Kaplan A, Sheppard D, Bridges AG, Shlomchik WD, Masopust D, Kaplan DH (2016) Stromal cells control the epithelial residence of DCs and memory $\mathrm{T}$ cells by regulated activation of TGF- $\beta$. Nat Immunol 17: $414-421$.

Moses HL, Roberts AB, Derynck R (2016) The discovery and early days of TGF- $\beta$ : a historical perspective. Cold Spring Harb Perspect Biol; e-pub ahead of print 1 July 2016; doi:10.1101/cshperspect.a021865.

Naka K, Hoshii T, Muraguchi T, Tadokoro Y, Ooshio T, Kondo Y, Nakao S, Motoyama N, Hirao A (2010) TGF- $\beta$-FOXO signalling maintains leukaemia-initiating cells in chronic myeloid leukaemia. Nature 463: 676-680.

Oka M, Iwata C, Suzuki HI, Kiyono K, Morishita Y, Watabe T, Komuro A, Kano MR, Miyazono K (2008) Inhibition of endogenous TGF- $\beta$ signaling enhances lymphangiogenesis. Blood 111: 4571-4579.

Oshimori N, Oristian D, Fuchs E (2015) TGF- $\beta$ promotes heterogeneity and drug resistance in squamous cell carcinoma. Cell 160: 963-976.

Padua D, Massagué J (2009) Roles of TGF $\beta$ in metastasis. Cell Res 19: 89-102.

Padua D, Zhang XH, Wang Q, Nadal C, Gerald WL, Gomis RR, Massagué J (2008) TGF $\beta$ primes breast tumors for lung metastasis seeding through angiopoietin-like 4. Cell 133: 66-77.

Pang MF, Georgoudaki AM, Lambut L, Johansson J, Tabor V, Hagikura K, Jin Y, Jansson M, Alexander JS, Nelson CM, Jakobsson L, Betsholtz C, Sund M, Karlsson MC, Fuxe J (2016) TGF- $\beta$ 1-induced EMT promotes targeted migration of breast cancer cells through the lymphatic system by the activation of CCR7/CCL21-mediated chemotaxis. Oncogene 35: 748-760.

Pardali E, ten Dijke P (2009) Transforming growth factor- $\beta$ signaling and tumor angiogenesis. Front Biosci 14: 4848-4861.

Peñuelas S, Anido J, Prieto-Sanchez RM, Folch G, Barba I, Cuartas I, GarciaDorado D, Poca MA, Sahuquillo J, Baselga J, Seoane J (2009) TGF- $\beta$ increases glioma-initiating cell self-renewal through the induction of LIF in human glioblastoma. Cancer Cell 15: 315-327.

Pickup M, Novitskiy S, Moses HL (2013) The roles of TGF $\beta$ in the tumour microenvironment. Nat Rev Cancer 13: 788-799.

Quante M, Tu SP, Tomita H, Gonda T, Wang SS, Takashi S, Baik GH, Shibata W, Diprete B, Betz KS, Friedman R, Varro A, Tycko B, Wang TC (2011) Bone marrow-derived myofibroblasts contribute to the mesenchymal stem cell niche and promote tumor growth. Cancer Cell 19: 257-272.

Reichl P, Dengler M, van Zijl F, Huber H, Fuhrlinger G, Reichel C, Sieghart W, Peck-Radosavljevic M, Grubinger M, Mikulits W (2015) Axl activates autocrine transforming growth factor- $\beta$ signaling in hepatocellular carcinoma. Hepatology 61: 930-941.

Roberts AB, Wakefield LM (2003) The two faces of transforming growth factor $\beta$ in carcinogenesis. Proc Natl Acad Sci USA 100: 8621-8623.

Rodon J, Carducci MA, Sepulveda-Sanchez JM, Azaro A, Calvo E, Seoane J, Brana I, Sicart E, Gueorguieva I, Cleverly AL, Pillay NS, Desaiah D, Estrem ST, Paz-Ares L, Holdhoff M, Blakeley J, Lahn MM, Baselga J (2015) First-in-Human Dose Study of the novel transforming growth factor- $\beta$ receptor I kinase inhibitor LY2157299 monohydrate in patients with advanced cancer and glioma. Clin Cancer Res 21: 553-560.

Scheel C, Eaton EN, Li SHJ, Chaffer CL, Reinhardt F, Kah KJ, Bell G, Guo W, Rubin J, Richardson AL, Weinberg RA (2011) Paracrine and autocrine signals induce and maintain mesenchymal and stem cell states in the breast. Cell 145: 926-940.

Stephen TL, Rutkowski MR, Allegrezza MJ, Perales-Puchalt A, Tesone AJ, Svoronos N, Nguyen JM, Sarmin F, Borowsky ME, Tchou J, Conejo-
Garcia JR (2014) Transforming growth factor $\beta$-mediated suppression of antitumor $\mathrm{T}$ cells requires FoxP1 transcription factor expression. Immunity 41: 427-439.

Tang B, Yoo N, Vu M, Mamura M, Nam JS, Ooshima A, Du Z, Desprez PY, Anver MR, Michalowska AM, Shih J, Parks WT, Wakefield LM (2007) Transforming growth factor- $\beta$ can suppress tumorigenesis through effects on the putative cancer stem or early progenitor cell and committed progeny in a breast cancer xenograft model. Cancer Res 67: 8643-8652.

Tang YN, Ding WQ, Guo XJ, Yuan XW, Wang DM, Song JG (2015) Epigenetic regulation of Smad2 and Smad3 by profilin-2 promotes lung cancer growth and metastasis. Nat Commun 6: 8230.

Wang C, Liu P, Wu H, Cui P, Li Y, Liu Y, Liu Z, Gou S (2016) MicroRNA323-3p inhibits cell invasion and metastasis in pancreatic ductal adenocarcinoma via direct suppression of SMAD2 and SMAD3. Oncotarget 7: 14912-14924.

Waning DL, Mohammad KS, Reiken S, Xie W, Andersson DC, John S, Chiechi A, Wright LE, Umanskaya A, Niewolna M, Trivedi T, Charkhzarrin S, Khatiwada P, Wronska A, Haynes A, Benassi MS, Witzmann FA, Zhen G, Wang X, Cao X, Roodman GD, Marks AR, Guise TA (2015) Excess TGF- $\beta$ mediates muscle weakness associated with bone metastases in mice. Nat Med 21: 1262-1271.

Weber CE, Kothari AN, Wai PY, Li NY, Driver J, Zapf MA, Franzen CA, Gupta GN, Osipo C, Zlobin A, Syn WK, Zhang J, Kuo PC, Mi Z (2014) Osteopontin mediates an MZF1-TGF- $\beta 1$-dependent transformation of mesenchymal stem cells into cancer-associated fibroblasts in breast cancer. Oncogene 34: 4821-4833.

Yan HH, Jiang J, Pang Y, Achyut BR, Lizardo M, Liang X, Hunter K, Khanna C, Hollander C, Yang L (2015) CCL9 induced by TGF $\beta$ signaling in myeloid cells enhances tumor cell survival in the premetastatic organ. Cancer Res 75: 5283-5298.

Yan HH, Pickup M, Pang YL, Gorska AE, Li ZY, Chytil A, Geng YP, Gray JW, Moses HL, Yang L (2010) Gr- $1^{+} \mathrm{CD}_{11 \mathrm{~b}}{ }^{+}$myeloid cells tip the balance of immune protection to tumor promotion in the premetastatic lung. Cancer Res 70: 6139-6149.

Yang L, Huang J, Ren X, Gorska AE, Chytil A, Aakre M, Carbone DP, Matrisian LM, Richmond A, Lin PC, Moses HL (2008) Abrogation of TGF $\beta$ signaling in mammary carcinomas recruits $\mathrm{Gr}-1^{+} \mathrm{CD} 11 \mathrm{~b}^{+}$myeloid cells that promote metastasis. Cancer Cell 13: 23-35.

Yang L, Pang Y, Moses HL (2010) TGF- $\beta$ and immune cells: an important regulatory axis in the tumor microenvironment and progression. Trends Immunol 31: 220-227.

You HN, Ding W, Rountree CB (2010) Epigenetic regulation of cancer stem cell marker CD133 by transforming growth factor- $\beta$. Hepatology 51 : $1635-$ 1644.

Yuan JH, Yang F, Wang F, Ma JZ, Guo YJ, Tao QF, Liu F, Pan W, Wang TT, Zhou CC, Wang SB, Wang YZ, Yang Y, Yang N, Zhou WP, Yang GS, Sun SH (2014) A long noncoding RNA activated by TGF- $\beta$ promotes the invasion-metastasis cascade in hepatocellular carcinoma. Cancer Cell 25: 666-681.

Zeisberg EM, Potenta S, Xie L, Zeisberg M, Kalluri R (2007) Discovery of endothelial to mesenchymal transition as a source for carcinomaassociated fibroblasts. Cancer Res 67: 10123-10128.

Zhou F, Drabsch Y, Dekker TJ, de Vinuesa AG, Li Y, Hawinkels LJ, Sheppard KA, Goumans MJ, Luwor RB, de Vries CJ, Mesker WE, Tollenaar RA, Devilee P, Lu CX, Zhu H, Zhang L, Dijke PT (2014) Nuclear receptor NR4A1 promotes breast cancer invasion and metastasis by activating TGF- $\beta$ signalling. Nat Commun 5: 3388.

Zhuang J, Lu Q, Shen B, Huang X, Shen L, Zheng X, Huang R, Yan J, Guo H (2015) TGF $\beta 1$ secreted by cancer-associated fibroblasts induces epithelialmesenchymal transition of bladder cancer cells through lncRNAZEB2NAT. Sci Rep 5: 11924.

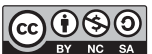

This work is licensed under the Creative Commons Attribution-Non-Commercial-Share Alike 4.0 International License. To view a copy of this license, visit http:// creativecommons.org/licenses/by-nc-sa/4.0/ 